\title{
Psychometric properties of the Minnesota Living with Chronic Heart Failure Questionnaire in a Colombian population
}

\author{
Propiedades psicométricas del "Minnesota Living with Chronic \\ Heart Failure Questionnaire" en una Población Colombiana
}

\author{
Lyda-Z Rojas ${ }^{1,2}$; Juliana-A Hernández ${ }^{1}$; Silvia-J Trujillo ${ }^{1}$; Zayne-M Roa ${ }^{1}$; Adriana-M Jurado ${ }^{1}$; \\ Luis-E Echeverría ${ }^{1}$; Taulant Muka²; Oscar-H Franco ${ }^{2,3}$
}

\begin{abstract}
Suggested citation: Rojas LZ, Hernández JA, Trujillo SJ, Roa ZM, Jurado AM, Echeverría LE, et al. Psychometric properties of the Minnesota Living with Chronic Heart Failure Questionnaire in a Colombian population. Rev Univ Ind Santander Salud. 2019;51(1): 11-22. doi: http://dx.doi.org/10.18273/revsal.v51n1-2019002 @) (1)
\end{abstract}

\begin{abstract}
Introduction: Although the Minnesota Living with Heart Failure Questionnaire (MLHF-Q) is one of the most widely used tools to assess Health-Related Quality of Life (HRQoL) in patients with chronic heart failure (CHF), it has not been validated in Latin American Spanish-speaking populations. Objective: We evaluated internal consistency and construct validity of the MLHF-Q in patients with CHF from Colombia. Methods: The Spanish version of the MLHF-Q was given to 200 patients. Cronbach's alpha was used to evaluate internal consistency. Confirmatory factorial Principal Component Analysis (PCA) and Rasch analysis were used to evaluate construct validity. The discriminative capacity was measured using the Mann-Whitney U test. Results: Median age was 64 years, $63 \%$ of the patients included in the study were men, and $79.5 \%$ had a left ventricular ejection fraction (LVEF) $\leq 45 \%$. The median of the total score of HRQoL was 40 points $(\mathrm{Q} 1=20$; Q3=55), physical dimension 11 points $(\mathrm{Q} 1=4$; Q3=23) and emotional dimension 7 points $(\mathrm{Q} 1=3$; Q3=13). Global internal consistency of MLHF-Q was $0.91(95 \% \mathrm{CI}$ 0.89 - 0.93). In the PCA, the three dimensions explained $47.7 \%$ and $54.0 \%$ in Rasch analysis, in which five items presented misfit. Worse HRQoL was observed among women than men in the emotional dimension $(p=0.047)$. Discriminative capacity for the overall score of the MLHF-Q and their subscales was observed in age and New York Heart Association (NYHA) functional class $(p<0.05)$. Conclusions: Our findings confirmed the three-factor structure of the MLHF-Q, and satisfactory level for internal consistency. Additionally, these results suggest that the questionnaire adequately reflects the severity of the disease. However, further studies are required to validate these findings in Colombian population and to evaluate the sensitivity to change of the MLHF-Q in longitudinal designs.
\end{abstract}

Keywords: Heart failure; Quality of life; Validation studies.

1. Fundación Cardiovascular de Colombia, Floridablanca, Santander, Colombia.

2. Erasmus University Medical Center, Rotterdam, The Netherlands.

3. University of Bern, Bern, Switzerland.

Correspondence: Lyda Z. Rojas. Address: Calle 155A No 23-58 Urbanización El Bosque. Box 681001 Floridablanca, Colombia. Phone number: 6399292 Ext. 344. Email: lydarojas@fcv.org 


\section{Resumen}

Introducción: El Minnesota Living with Heart Failure Questionnaire (MLHF-Q) es uno de los instrumentos más utilizados para medir la Calidad de Vida Relacionada con la Salud (CVRS) en pacientes con Falla cardíaca Crónica (FCC); sin embargo, éste no ha sido validado en poblaciones latinoamericanas hispanohablantes. Objetivo: Evaluar la consistencia interna y validez de constructo del MLHF-Q en pacientes con FCC de Colombia. Métodos: La versión en español del MLHF-Q fue diligenciada por 200 pacientes. La consistencia interna se evaluó con el Alpha de Cronbach. La validez de constructo fue examinada por dos métodos: Análisis de Componentes Principales (ACP) confirmatorio y análisis Rasch. Se evaluó la capacidad discriminativa del instrumento con la prueba UMann-Whitney. Resultados: Mediana de edad de 64 años, 63\% hombres y el 79.5\% de los participantes tenían fracción de eyección del ventrículo izquierdo (FEVI) $\leq 45 \%$. La mediana del puntaje total de CVRS fue 40 puntos $(\mathrm{Q} 1=20 ; \mathrm{Q} 3=55)$, dimensión física 11 puntos $(\mathrm{Q} 1=4 ; \mathrm{Q} 3=23)$ y dimensión emocional 7 puntos $(\mathrm{Q} 1=3 ; \mathrm{Q} 3=13)$. La consistencia interna fue 0.91 (IC 95\% 0.89 - 0.93). En el ACP, las tres dimensiones explicaron el $54.0 \%$ y $47.7 \%$ en el análisis Rasch, en éste último cinco ítems presentaron desajuste. Se observó peor CVRS en mujeres que en hombres en la dimensión emocional $(p=0.047)$ y se evidenció capacidad discriminativa de las subescalas y el puntaje total del MLHF-Q en la edad y la clase funcional New York Heart Association (NYHA) $(p<0.05)$. Conclusión: Nuestros hallazgos confirmaron la estructura de tres factores del MLHF-Q y un nivel satisfactorio para la consistencia interna. Adicionalmente, estos resultados sugieren que el cuestionario refleja adecuadamente la gravedad de la enfermedad. Sin embargo, se requieren estudios adicionales en población colombiana para validar estos hallazgos y evaluar la sensibilidad al cambio del MLHF-Q en diseños longitudinales.

Palabras clave: Insuficiencia cardíaca; Calidad de vida; Estudios de validación.

\section{Introduction}

Chronic Heart Failure (CHF) prevalence is over 5.8 million in the USA, and over 23 million worldwide ${ }^{1}$. In Latin America, estimated Heart Failure (HF) prevalence is $1 \%(95 \% \mathrm{CI}, 0.1$ to $2.7 \%)$ with 199 per 100,000 person-year ${ }^{2}$. The hospital readmission rates of patients with $\mathrm{HF}$ are $33 \%, 28 \%, 31 \%$, and $35 \%$ at $3,6,12$, and 24 to 60 months of follow-up (median duration of hospitalization of 7.0 days), with 1-year mortality rate of $24.5 \%(95 \%$ CI, 19.4 to $30.0 \%)$ and inhospital mortality of $11.7 \%$ (95\% CI, 10.4 to $13.0 \%)^{2}$. Although mortality has decreased in CHF, the estimated survival rate is $50 \%$ and $10 \%$ at five and ten years after diagnosis ${ }^{3}$.

The burden of the disease in CHF involves several limitations in patients carrying out daily life activities, and affects health-related quality of life (HRQoL) more severely than other chronic diseases ${ }^{4}$. Several studies have shown that HRQoL of patients with HF is worse than the general population, or patients with other chronic diseases ${ }^{4,5}$. Furthermore, the decline in quality of life of HF patients is not temporary, but rather progressive over time ${ }^{6}$. Nevertheless, measuring HRQoL in HF remains a challenge, and despite the existence of several instruments (generic and disease-specific) for assessing HRQoL, no consensus has been achieved on which instrument would be most suitable?
The Minnesota Living with Heart Failure Questionnaire (MLHF-Q) is a disease-specific instrument, consisting of 21 items addressing a wide range of HRQoL and it is the most frequently used internationally. Since 1987, the MLHF-Q has been translated into more than 30 languages, including Spanish ${ }^{8-13}$ and it is used as an outcome measure in multiple clinical trials showing the best psychometric properties as to validity, reliability and sensitivity to change ${ }^{14-17}$.

Even though Spanish is spoken by $95 \%$ of Latin America's population, Brazil, where Portuguese is spoken, is the only regional country where the MLHF-Q has been validated ${ }^{18}$, while Colombia has no data available on the evaluation of the reliability and validity of the MLHF-Q. Therefore, we aimed to evaluate the internal consistency and construct validity of the MLHF-Q in patients with CHF in Colombia.

\section{Methods}

\section{Study population}

A cross-sectional study was conducted between February and October 2015 in the Heart Failure and Heart Transplant Clinic of Cardiovascular Foundation in Floridablanca city, Santander-Colombia. We included patients if they (i) were 18 years old or older and (ii) had a confirmed HF medical diagnosis by a cardiologist. Patients with mental sphere alterations or communication 
limitations were excluded. All patients gave written informed consent and the Research Ethic Committee of the institution approved the research protocol.

In calculating our sample size, care was taken to comply with the 10-patient-per-analized-item criterion considered adequate for factorial analysis ${ }^{19}$. The sample was selected in a non-probabilistic way; all patients were invited to participate consecutively by a previously trained nurse who conducted the interviews upon medical control appointments.

\section{Clinical screening}

HRQoL was measured with the MLHF-Q ${ }^{11}$, a specific self-report instrument for CHF patients. HRQoL questionnaire is made up of 21 items graded by the patient using a 6-point Likert-type scale ranging from 0 (no impairment) to 5 (very much impairment). The MLHF-Q groups the items in three dimensions: physical (8 items), emotional (5 items), and the overall score for HRQoL (21 items). Eight separate items, which do not assess a single construct or dimension of HRQoL, measure social and economic impairments of patients with $\mathrm{HF}$ and contribute to the overall score. The total score has a range between 0 and 105 points, the physical dimension (between 0 and 40), the emotional dimension (0 and 25) and the separate items on the socio-economic impairments (0 and 40). High scores on the MLHF-Q scale indicate impaired HRQoL. The MLHF-Q has a global internal consistency measured by Cronbach's alpha of 0.94 (95\% CI, 0.91 to 0.95 ) and general intraclass correlation coefficient of 0.84 , characteristics that make it suitable for use ${ }^{17}$.

\section{Statistical analysis}

Continuous variables are reported as median and quartiles (Q) unless stated otherwise, and categorical variables are presented as percentages. Internal consistency was evaluated through Cronbach's alpha coefficient ${ }^{20}$. Kaiser-Meyer-Oklin's (KMO) index and Bartlett's test of sphericity were estimated to establish the pertinence of factorial analysis. KMO $\geq 0.7$ was considered acceptable ${ }^{21,22}$.

To evaluate construct validity of the questionnaire, two different approaches were used: first, the structure of the model originally proposed by Rector and Cohn ${ }^{8}$ was examined by means of confirmatory factorial principal component analysis (PCA). Dimensional structure was identified through varimax-type octagonal rotation, factor loading, and those $\geq 0.4$ were considered acceptable ${ }^{13,23}$. Second, polytomous Rasch rating scale model was used to assess each specific questionnaire dimension according to the factorial structure proposed by literature ${ }^{24}$. Thus, the first step was to evaluate the functioning of rating scale categories. A clearly progressive level of difficulty across item categories was expected as a criterion of adequate function. We also examined the standardized (ZSTD) fit statistics of persons for whom a score between \pm 3 was expected.

For dimensionality evaluation, which is a fundamental requirement for construct validity, we applied the following criteria: (i) mean square information-weighted statistic (infit) and the outlier-sensitive statistic (outfit), with values between 0.7 and 1.3 indicate a good fit (ii) PCA of the residuals ${ }^{25}$. Unidimensionality was violated if, besides the first factor, other factors had eigenvalues $>3$, and the local dependency was assessed through the item residual correlations where values $>0.5$ may indicate that the response to one item may be determined by another. To detect the presence of differential item functioning (DIF), which occurs when groups within the sample respond differently from an individual item; we compared distinct levels of the trait by sex and age group ( $\leq 65$ vs. $>65$ years). A Welch's t statistically significant $(p<0.05)$, and a difficulty difference $\geq 0.5$ logits were considered evidence of uniform DIF.

Finally, discriminative capacity of the questionnaire was assessed by its ability to differentiate among subgroups of patients with different levels of CHF severity, taking into account the following hypothesis: women, higher age, superior New York Heart Association (NYHA) functional class and Left Ventricular Ejection Fraction (LVEF) under $45 \%$ will have higher scores of the MLHF-Q, by using the Mann-Whitney U test. All statistical tests were two-sided and a $p$-value $<0.05$ was considered significant. Data were analyzed using Stata Statistical Software, version 14 and Winsteps 3.80.0.

\section{Results}

\section{Characteristics of the study population}

The proportion of missing data was $0 \%$. During recruitment period, two hundred CHF patients fulfilled the selection criteria, agreed to participate and completed the questionnaire. Median age of participants was $64(\mathrm{Q} 1=53$; Q3=73) years old, $63.0 \%$ were men, $79.5 \%$ had a LVEF $\leq 45 \%$, and $24.0 \%$ subjects were in NYHA functional class III-IV. Sociodemographic and clinical characteristics of the study population are shown in Table 1. 
Table 1. Sociodemographic and clinical characteristics of the study population $(n=200)$.

\begin{tabular}{|c|c|}
\hline Variable & n $(\%)$ \\
\hline Age $(\text { years })^{\mathrm{a}}$ & $64(53-73)$ \\
\hline \multicolumn{2}{|l|}{ Sex } \\
\hline Men & $126(63.0)$ \\
\hline Women & $74(37.0)$ \\
\hline \multicolumn{2}{|l|}{ Socioeconomic status } \\
\hline Low & $124(62.0)$ \\
\hline Medium & $64(32.0)$ \\
\hline High & $12(6.0)$ \\
\hline \multicolumn{2}{|l|}{ Education status } \\
\hline Less than high school & $132(66.0)$ \\
\hline High school & $40(20.0)$ \\
\hline Greater than high school & $28(14.0)$ \\
\hline \multicolumn{2}{|l|}{ Marital status } \\
\hline Married/living in a free union & $134(67.0)$ \\
\hline Widowers & $27(13.5)$ \\
\hline Single & $24(12.0)$ \\
\hline Divorced & $15(7.5)$ \\
\hline \multicolumn{2}{|l|}{ Employment status } \\
\hline Unemployed & $71(35.5)$ \\
\hline Employees & $50(25.0)$ \\
\hline Pensioner & $43(21.5)$ \\
\hline Housewives & $22(11.0)$ \\
\hline Students & $14(7.0)$ \\
\hline \multicolumn{2}{|l|}{ Etiology of Chronic heart failure } \\
\hline Ischemic & $60(30.0)$ \\
\hline Chagas disease & $40(20.0)$ \\
\hline Idiopathic & $29(14.5)$ \\
\hline Multifactorial & $27(13.5)$ \\
\hline Hipertensive & $14(7.0)$ \\
\hline Valvular & $12(6.0)$ \\
\hline Other (congenital, viral, peripartum and others) & $18(9.0)$ \\
\hline \multicolumn{2}{|l|}{ LVEF (\%) } \\
\hline$\leq 45$ & $159(79.5)$ \\
\hline$>45$ & $41(20.5)$ \\
\hline \multicolumn{2}{|l|}{ Functional class NYHA } \\
\hline I-II & $152(76.0)$ \\
\hline III-IV & $48(24.0)$ \\
\hline \multicolumn{2}{|l|}{ Charlson comorbidity index } \\
\hline 1 & $101(50.5)$ \\
\hline 2 & $58(29.0)$ \\
\hline 3 & $27(13.5)$ \\
\hline$>3$ & $14(7.0)$ \\
\hline \multicolumn{2}{|l|}{ Medications } \\
\hline Beta-Blocker & $194(97.0)$ \\
\hline ACE inhibitor & $68(34.0)$ \\
\hline Angiotensin receptor blocker & $110(55.0)$ \\
\hline Aldosterone antagonist & $165(82.5)$ \\
\hline Diuretic & $126(63.0)$ \\
\hline Digoxin & $58(29.0)$ \\
\hline
\end{tabular}

Source: authors. ${ }^{a}$ Median (first and third quartile). LVEF=Left ventricular ejection fraction; NYHA=New York Heart Association; $\mathbf{A C E}=$ Angiotensin-converting enzyme.

\section{Psychometric analysis}

\section{Internal reliability}

Cronbach's alphas coefficients ranged from 0.73 (social dimension) to 0.91 (physical dimension and total score) in the MLHF-Q, indicating satisfactory level for internal consistency. Descriptive analysis and internal consistency of the MLHF-Q are shown in Table 2 and Supplementary Material Table S1.

Table 2. Descriptive analysis and internal consistency of the Minnesota Living with Heart Failure Questionnaire ( $n=200)$.

\begin{tabular}{lcccccc}
$\begin{array}{l}\text { Quality of Number } \\
\text { life }\end{array}$ & $\begin{array}{c}\text { Median } \\
\text { of items }\end{array}$ & R1-Q3) & Range & & & \\
\hline $\begin{array}{l}\text { Physical } \\
\text { dimension }\end{array}$ & 8 & $11(4-23)$ & $0-40$ & 0.91 & $0.89-0.93$ \\
$\begin{array}{l}\text { Emotional } \\
\text { dimension }\end{array}$ & 5 & $7(3-13)$ & $0-24$ & 0.80 & $0.76-0.85$ \\
Social & 8 & $16(10-22)$ & $0-32$ & 0.73 & $0.68-0.78$ \\
Total score & 21 & $40(20-55)$ & $0-95$ & 0.91 & $0.90-0.93$ \\
\hline
\end{tabular}

Source: authors. ${ }^{\mathrm{a} Q 1-Q 3}=$ First and third quartile.

\section{Construct validity}

The KMO statistic was 0.90 , indicating sampling adequacy (Supplementary Material Table S2) and Bartlett's test of sphericity was statistically significant $\left(\operatorname{chi}^{2}(210)=2126.20 ; p=0.000\right)$, suggesting that data were appropriate to be subjected to a factorial analysis ${ }^{22}$. All items in the first factor were associated to signs and symptoms of HF; this factor was identified such as physical dimension. The second factor, included four items of five items from the original questionnaire, and they were related to the patient's psychological response to disease; this factor was recognized as the emotional dimension. Finally, three items in the third factor were correlated to the patient's social relationships, thus this factor was named the social dimension. Then, confirmatory factorial PCA of three factors explained $54.03 \%$ of total variation in the study population, of which $30.6 \%$ was explained by the first factor, $15.8 \%$ the second factor and $7.6 \%$ the third dimension. Eigenvalue was 6.43 for the physical, 3.31 for the emotional, and 1.59 for the social dimension (Supplementary Material Table S3).

Table 3 shows factorial analysis, five of the 21 items demonstrated factor loadings between 0.4 and 0.6 ; four between 0.6 and 0.7 ; six between 0.7 and 0.8 ; four items had factor loadings $>0.8$ and, two items (14 and 16) did not adequately load (loading <0.4). Additionally, in Table 3 we can distinguish physical, 
emotional and social dimensions. Also, items 1, 8, 9, 10 (social) and 20 (emotional) have been reclassified in physical dimension. Conversely, emotional dimension is preserved almost entirely, except for item 20. Finally, item 8 could belong to both, the physical and social dimension.

Table 3. Factorial principal component analysis with orthogonal varimax rotation (loadings) of the Minnesota Living with Heart Failure Questionnaire.

\begin{tabular}{|c|c|c|c|c|}
\hline Item & $\begin{array}{c}\text { Factor1 } \\
\text { (Physical) }\end{array}$ & $\begin{array}{c}\text { Factor2 } \\
\text { (Emotional) }\end{array}$ & $\begin{array}{l}\text { Factor3 } \\
\text { (Social) }\end{array}$ & Uniqueness \\
\hline 1. Swelling in your ankles, legs & $0.5120^{\mathrm{a}}$ & & & 0.6223 \\
\hline 2. Resting during day & $0.7834^{\mathrm{b}}$ & & & 0.3565 \\
\hline 3. Walking or climbing stairs difficult & $0.8388^{\mathrm{b}}$ & & & 0.2816 \\
\hline 4. Working around house difficult & $0.8264^{\mathrm{b}}$ & & & 0.2747 \\
\hline 5. Away from home difficult & $0.7965^{\mathrm{b}}$ & & & 0.3158 \\
\hline 6. Sleeping difficult & $0.5547^{\mathrm{b}}$ & & & 0.6568 \\
\hline 7. Relating to or doing things with friends or family difficult & $0.6013^{\mathrm{b}}$ & & & 0.5491 \\
\hline 8. Working to earn a living difficult & $0.7058^{\mathrm{a}}$ & & $0.4391^{\mathrm{a}}$ & 0.2883 \\
\hline 9. Recreational activities difficult & $0.6374^{\mathrm{a}}$ & & & 0.4775 \\
\hline 10. Sexual activities difficult & $0.4471^{\mathrm{a}}$ & & & 0.7653 \\
\hline 11. Eating less foods I like & & & $0.6183^{\mathrm{a}}$ & 0.5349 \\
\hline 12. Shortness of breath & $0.6765^{\mathrm{b}}$ & & & 0.4462 \\
\hline 13. Fatigue & $0.8216^{\mathrm{b}}$ & & & 0.2710 \\
\hline 14. Hospitalization & ---- & ---- & ---- & 0.7383 \\
\hline 15. Medical costs & & & $0.7819^{\mathrm{a}}$ & 0.3630 \\
\hline 16. Side effects from medications & ---- & ---- & ---- & 0.8387 \\
\hline 17. Feeling burden to family or friends & & $0.7972^{\mathrm{c}}$ & & 0.3314 \\
\hline 18. Feeling loss of self-control & & $0.8719^{\mathrm{c}}$ & & 0.2252 \\
\hline 19. Being worried & & $0.7854^{\mathrm{c}}$ & & 0.3146 \\
\hline 20. Difficulty concentrating or remembering & $0.4947^{\mathrm{c}}$ & & & 0.6825 \\
\hline 21. Being depressed & & $0.7746^{\mathrm{c}}$ & & 0.3204 \\
\hline
\end{tabular}



Regarding Rasch analysis of the total score, the average measures of the rating scale of the MLHF-Q were ordered, progressing from -0.84 logits for rating scale category zero (no impairment) to 0.27 logits for rating scale category of five (very much impairment); disordered thresholds (response categories not working logically) were corrected by combining adjacent categories (Supplementary Material Figure S1); the result was a 3-point scale that met the criteria for rating scale. Eight persons had a ZSTD exceeding the value expected and were excluded from the analysis.

The person separation was 2.56 and reliability 0.87 ; for items these statistics were 5.00 and 0.96 , respectively. Items 15, 16, 20, 14 and 10 showed fit statistics (Outfit, Infit) out of the established range for the analysis; statistics are shown in Table 4. In the PCA of residuals, 21 items and 192 persons explained the $42.0 \%$. In the first contrast, we observed 3.3 eigenvalues with residuals correlations higher than 0.50 . Items 1,15 , 16 and 17 had a difference in difficulty $\geq 0.5$ logits by groups of age with Welch $p$ values under 0.05 . There was no evidence of uniform DIF by sex groups. After removing the five misfit items, the overall fit of the data improved, with $47.7 \%$ of raw variance explained and only two items ( 6 and 11) maintaining their fit statistics above the range.

In the analysis of physical, emotional and social dimensions, disorders of the rating scale were not observed, in fact, all analyses were made with the original MLHF-Q codification. Social dimension's items explained $44.8 \%$ of the variance and had 1.7 eigenvalues in the first contrast, the residual did not present any important correlation. Item 8 (working to earn a living difficult) of social dimension had a slightly 
lower value of the range. The eight items of physical dimension presented 2 eigenvalues in the first contrast and explained $57.4 \%$ of the raw variance; two of the items were above and one item was below expected range as shown in Table 4.

Table 4. Severity levels, standard errors, and goodness-of-fit indexes of the 21 MLHF-Q items and by dimensions using Rasch analysis $(\mathrm{n}=192)$.

\begin{tabular}{|c|c|c|c|c|c|}
\hline \multirow{2}{*}{ Items } & \multirow{2}{*}{ Description } & \multirow{2}{*}{$(\operatorname{logit})^{\mathrm{a}}$} & \multirow{2}{*}{ SE } & \multicolumn{2}{|c|}{ MNSQ } \\
\hline & & & & Infit & Outfit $^{b}$ \\
\hline \multicolumn{6}{|l|}{ Total } \\
\hline 15 & Medical costs & -1.04 & 0.11 & 1.57 & 1.91 \\
\hline 16 & Side effects from medications & 0.30 & 0.11 & 1.28 & 1.59 \\
\hline 20 & Difficulty concentrating or remembering & -0.38 & 0.11 & 1.13 & 1.56 \\
\hline 14 & Hospitalization & 1.07 & 0.13 & 1.48 & 1.41 \\
\hline 10 & Sexual activities difficult & -0.34 & 0.11 & 1.35 & 1.33 \\
\hline 6 & Sleeping difficult & 0.09 & 0.11 & 1.13 & 1.20 \\
\hline 11 & Eat less food you like & -1.58 & 0.12 & 1.17 & 1.10 \\
\hline 9 & Recreational activities difficult & -0.40 & 0.11 & 1.10 & 1.09 \\
\hline 18 & Feeling a loss of self-control & 0.49 & 0.12 & 1.10 & 1.07 \\
\hline 17 & Feeling burden to family or friends & 0.63 & 0.12 & 1.08 & 0.96 \\
\hline 1 & Swelling in your ankles, legs & 0.90 & 0.13 & 1.01 & 0.98 \\
\hline 19 & Being worried & -0.09 & 0.11 & 1.00 & 0.99 \\
\hline 7 & Relating to or doing things with friends or family difficult & 0.60 & 0.12 & 0.92 & 0.83 \\
\hline 21 & Being depressed & 0.40 & 0.12 & 0.89 & 0.88 \\
\hline 8 & Working to earn a living difficult & -0.65 & 0.11 & 0.81 & 0.73 \\
\hline 3 & Walking or climbing stairs difficult & -0.43 & 0.11 & 0.77 & 0.72 \\
\hline 5 & Being away from home difficult & 0.14 & 0.11 & 0.77 & 0.66 \\
\hline 12 & Shortness of breath & 0.53 & 0.12 & 0.73 & 0.76 \\
\hline 4 & Working around house difficult & -0.02 & 0.11 & 0.73 & 0.65 \\
\hline 2 & Resting during day & 0.04 & 0.11 & 0.60 & 0.57 \\
\hline 13 & Fatigue & -0.25 & 0.11 & 0.57 & 0.56 \\
\hline \multicolumn{6}{|l|}{ Physical } \\
\hline 6 & Sleeping difficult & -0.04 & 0.06 & 1.70 & 1.88 \\
\hline 7 & Relating to or doing things with friends or family difficult & 0.39 & 0.07 & 1.43 & 1.55 \\
\hline 12 & Shortness of breath & 0.33 & 0.07 & 1.07 & 1.26 \\
\hline 5 & Being away from home difficult & 0.03 & 0.07 & 0.95 & 0.83 \\
\hline 4 & Working around house difficult & -0.05 & 0.06 & 0.85 & 0.81 \\
\hline 3 & Walking or climbing stairs difficult & -0.36 & 0.06 & 0.80 & 0.75 \\
\hline 2 & Resting during day & -0.06 & 0.06 & 0.78 & 0.75 \\
\hline 13 & Fatigue & -0.24 & 0.06 & 0.60 & 0.65 \\
\hline \multicolumn{6}{|c|}{ Emotional } \\
\hline 20 & Difficulty concentrating or remembering & -0.43 & 0.06 & 1.72 & 2.30 \\
\hline 17 & Feeling burden to family or friends & 0.30 & 0.07 & 0.93 & 0.86 \\
\hline 19 & Being worried & -0.19 & 0.06 & 0.80 & 0.77 \\
\hline 21 & Being depressed & 0.09 & 0.07 & 0.74 & 0.64 \\
\hline 18 & Feeling a loss of self-control & 0.23 & 0.07 & 0.70 & 0.62 \\
\hline \multicolumn{6}{|l|}{ Social } \\
\hline 10 & Sexual activities difficult & -0.08 & 0.05 & 1.25 & 1.29 \\
\hline 16 & Side effects from medications & 0.24 & 0.05 & 1.10 & 1.28 \\
\hline 14 & Hospitalization & 0.51 & 0.06 & 1.18 & 1.14 \\
\hline 15 & Medical costs & -0.33 & 0.05 & 1.07 & 1.17 \\
\hline 9 & Recreational activities difficult & -0.08 & 0.05 & 0.98 & 0.93 \\
\hline 11 & Eat less food you like & -0.55 & 0.05 & 0.86 & 0.90 \\
\hline 1 & Swelling in your ankles, legs & 0.47 & 0.05 & 0.87 & 0.82 \\
\hline 8 & Working to earn a living difficult & -0.20 & 0.05 & 0.68 & 0.63 \\
\hline
\end{tabular}

Source: authors. ${ }^{a} \delta$ level of severity (higher values indicate higher severity). ${ }^{b}$ Expected range 0.7 - 1.3. MLHF-Q=Minnesota Living with Heart Failure Questionnaire; SE=Standard error; MNSQ=Mean square fit statistic; Infit=Inlier-sensitive fit; Outfit=Outlier-sensitive fit. 
In the emotional dimension, one item presented a severe misfit Table 4, the variance explained by these items was $54.0 \%$ and had 1.7 eigenvalues in the first contrast; correlation of -0.51 between items 19 and 20 was found. Eliminating item 20 and analyzing the remaining four items, all statistics were into the expected values (Supplementary Material Table S4) and the variance explained improved (Supplementary Material Table S5). It was not detected uniform DIF by sex or age group in any dimension. Wright maps are presented for each dimension evaluated (Supplementary Material Figure S2).

\section{Contrast validity}

Discriminative capacity of the MLHF-Q subscales and for the overall score was observed in age and NYHA functional class $(p<0.05)$. Worse HRQoL was observed among women than men in the emotional dimension $(p=0.047)$. Although higher HRQoL impairment was evident in LVEF $\leq 45 \%$ compared with LVEF $>45 \%$ patients, it was not statistically significant (Supplementary Material Table S6).

\section{Discussion}

To the best of our knowledge, the present work is the first study that has assessed the psychometric properties of the MLHF-Q in a Spanish-speaking population of Latin America. We have evaluated the internal consistency, construct validity through the two methods (PCA and Rasch analysis), and the discriminative capacity of the MLHF-Q in outpatients with CHF in Colombia.

\section{Interpretation of findings}

The reliability of subscales and overall MLHF-Q showed a Cronbach's alpha acceptable to excellent, with coefficients similar to those in other populations: Australia, France, Hungary, Yugoslavia (physical dimension $\alpha=0.91$ ); Hungary, Poland, Sweden (emotional dimension $\alpha=0.80$ ); Israel, Italy (social dimension $\alpha=0.73$ ), and Denmark, Spain, Yugoslavia (total score $\alpha=0.91)^{23,26}$.

Regarding construct validity, we found that the three factors explain $47.7 \%$ and $54.03 \%$ of the overall score in the Rasch analysis and PCA, respectively, with similar results previously reported by another $\operatorname{study}^{27}$, while in other studies the variance explained by these three factors has been higher (64.1 to $72 \%)^{9,10,19,28}$. Also, we found the following similarities with other authors; Heo, et al. ${ }^{27}$ evidenced that items ( 1 and 9) were loaded on physical dimension and items (14 and 16) presented loading $<0.4$. Ho, et al. ${ }^{19}$ showed that item 1 was loaded on physical dimension. Finally, Moon, et al..$^{28}$ found that items (1, 9 and 10) were loaded on physical dimension.

Item 1 (Swelling in your ankles, legs) is part of the social dimension (another dimension) from original version; however, it has been reported that up two thirds of patients admitted with acute HF presented hypervolemia signs such as jugular venous distension and peripheral edema, typical physiopathological manifestations of $\mathrm{HF}^{29-30}$, which support its correlation to the physical dimension. On the other hand, determine the most plausible dimension for item 10 (sexual activities difficult) is complicated, due to the multifactorial explanation (psychological, emotional, physical and medical) of HF patients' sexual activity ${ }^{31}$. Also, possible explanations for the differences found in the factor structure, variance explained, and eigenvalues with other authors could be sample size, culture, demographics and clinical characteristics, among others ${ }^{10,17}$.

The MLHF-Q is interpreted by its total score, which results of averaging the score of all 21 items. However, this assumes that the total score is unidimensional. Nevertheless, Rasch analysis for the total score did not find evidence of unidimensional functioning. Moreover, it demonstrated misfitting of five items $(10,14,15,16$, 20 ), and therefore confirming the existence of some problematic items in the composition of the total score. Elimination of items has been reported as a solution ${ }^{10,27}$. Exclusion of problematic items in our study improved the general fit to the Rasch model.

Similar findings have been reported by Munyombwe, et al. ${ }^{10}$ who found that several items $(7,8,10,14,16)$ presented misfit. Also, Bilbao, et al. ${ }^{24}$ reported two misfitting items (1 and 10). Considering that misfitting items have been identified in a third factor presenting the social dimension, as also shown in the current study, several authors have suggested to add a third factor to the total score $e^{9,10,19,23,28}$. However, it remains a challenge to reach a consensus on which of the different social factors proposed is the most appropriate and has the best psychometric properties, and therefore, future studies should examine further and use confirmatory techniques.

Regarding to response categories, we found difficulties in distinguishing between the response options very little (1) and little (2), or much (4) and very much (5). This pattern was also reported by Munyombwe, et al. ${ }^{10}$, who suggests that it could be explained by the sample size or an excess of response categories. 
According to the findings of the item-map graphics for the subscales, some patients are in the bottom of the emotional and physical subscales person-item maps, denoting floor effects. This finding is consistent with Munyombwe, et al. ${ }^{10}$, and suggests that those subscales need more items to cover all the levels of the underlying trait. Nevertheless, some studies have reported either floor or ceiling effect in the analysis of total score of the MLHF-Q ${ }^{10}$.

In relation to other variables that measure different stages of disease severity, our results are consistent with a priori hypothesis. The MLHF-Q scores clearly discriminate between different stages of NYHA functional class and age. This has also been observed in both observational studies ${ }^{9,11,13}$, as well as clinical trials, where it is the ideal setting for assessing sensitivity to change ${ }^{32-34}$.

\section{Strengths and limitations}

The strengths of our study include an adequate sample size, as also shown by the KMO statistic. Also, we provide complete analyses of the structural validity, using both factorial PCA and Rasch analysis. The present study has, however, some important limitations to consider. First, our study was conducted in a single HF center. Accordingly, study results cannot be considered a representative description of the HRQoL of all Colombia's HF clinics. Second, the MLHF-Q is a self-administered questionnaire and, in our study it was applied by a nurse because a high percentage of our population had low educational level, and therefore it could have affected the measurement of the HRQoL.

\section{Conclusions}

In conclusion, we have assessed the content, the internal consistency, construct and discriminative capacity of the MLHF-Q in patients with CHF from Colombia. We have confirmed the three-factor structure of MLHF-Q such as previous studies, and satisfactory level for internal consistency. Additionally, these results suggest that the questionnaire adequately reflects the severity of the disease. However further studies are required in Colombian population to validate these findings and to evaluate the sensitivity to change of the MLHF-Q in longitudinal designs.

\section{Acknowledgements}

The authors are grateful to patients participating in this study.

\section{Conflict of interest}

The authors declare no conflicts of interest.

\section{References}

1. Roger VL. Epidemiology of heart failure. Circ Res. 2013; 113(6): 646-659. doi: 10.1161/ CIRCRESAHA.113.300268.

2. Ciapponi A, Alcaraz A, Calderon M, Matta MG, Chaparro M, Soto N, et al. Burden of heart failure in Latin América: a systematic review and metaanalysis. Rev Esp Cardiol (Engl Ed). 2016; 69(11): 1051-1060. doi: 10.1016/j.rec.2016.04.054.

3. Escobar A, Garcia-Perez L, Navarro G, Bilbao A, Quiros R, group C-HS. A one-year mortality clinical prediction rule for patients with heart failure. Eur $\mathrm{J}$ Intern Med. 2017. doi: 10.1016/j.ejim.2017.06.013.

4. Jaarsma T, Johansson P, Agren S, Stromberg A. Quality of life and symptoms of depression in advanced heart failure patients and their partners. Curr Opin Support Palliat Care. 2010; 4(4): 233 237. doi: 10.1097/SPC.0b013e328340744d.

5. Juenger J, Schellberg D, Kraemer S, Haunstetter A, Zugck C, Herzog W, et al. Health related quality of life in patients with congestive heart failure: comparison with other chronic diseases and relation to functional variables. Heart. 2002; 87(3): 235-241.

6. Allen LA, Stevenson LW, Grady KL, Goldstein NE, Matlock DD, Arnold RM, et al. Decision making in advanced heart failure: a scientific statement from the American Heart Association. Circulation. 2012; 125(15): 1928-1952. doi: 10.1161/ CIR.0b013e31824f2173.

7. Berry C, McMurray J. A review of quality-of-life evaluations in patients with congestive heart failure. Pharmacoeconomics. 1999;16(3): 247-271. doi: 10.2165/00019053-199916030-00003.

8. Rector TS, Cohn JN. Assessment of patient outcome with the Minnesota Living with Heart Failure questionnaire: reliability and validity during a randomized, double-blind, placebo-controlled trial of pimobendan. Pimobendan Multicenter Research Group. Am Heart J. 1992; 124(4): 1017-1025.

9. Lambrinou E, Kalogirou F, Lamnisos D, Middleton N, Sourtzi P, Lemonidou C, et al. Evaluation of the psychometric properties of the Greek version of the Minnesota Living With Heart Failure questionnaire. J Cardiopulm Rehabil Prev. 2013; 33(4): 229-233. doi: 10.1097/HCR.0b013e3182930cbb.

10. Munyombwe T, Hofer S, Fitzsimons D, Thompson DR, Lane D, Smith K, et al. An evaluation of the Minnesota Living with Heart Failure Questionnaire 
using Rasch analysis. Qual Life Res. 2014; 23(6): 1753-1765. doi: 10.1007/s11136-013-0617-0.

11. Garin O, Soriano N, Ribera A, Ferrer M, Pont A, Alonso J, et al. Validation of the Spanish version of the Minnesota Living with Heart Failure Questionnarie. Rev Esp Cardiol. 2008; 61(3): 251-259.

12. Parajon T, Lupon J, Gonzalez B, Urrutia A, Altimir $\mathrm{S}$, Coll R, et al. Use of the Minnesota Living With Heart Failure Quality of Life Questionnaire in Spain. Rev Esp Cardiol. 2004; 57(2): 155-160.

13. Naveiro-Rilo JC, Diez-Juarez DM, Romero Blanco A, Rebollo-Gutierrez F, Rodriguez-Martinez A, Rodriguez-Garcia MA. Validation of the Minnesota living with heart failure questionnaire in primary care. Rev Esp Cardiol. 2010; 63(12): 1419-1427.

14. Garin O, Herdman M, Vilagut G, Ferrer M, Ribera A, Rajmil L, et al. Assessing health-related quality of life in patients with heart failure: a systematic, standardized comparison of available measures. Heart Fail Rev. 2014; 19(3): 359-367. doi: 10.1007/ s10741-013-9394-7.

15. Middel B, Bouma J, de Jongste M, van Sonderen E, Niemeijer MG, Crijns H, et al. Psychometric properties of the Minnesota Living with Heart Failure Questionnaire(MLHF-Q). Clin Rehabil.2001; 15(5): 489-500. doi: 10.1191/026921501680425216.

16. Zanolla L, Zardini P. Selection of endpoints for heart failure clinical trials. Eur J Heart Fail. 2003; 5(6): 717-723.

17. Garin O, Ferrer M, Pont A, Rue M, Kotzeva A, Wiklund I, et al. Disease-specific health-related quality of life questionnaires for heart failure: a systematic review with meta-analyses. Qual Life Res. 2009; 18(1): 7185. doi: 10.1007/s11136-008-9416-4.

18. Saccomann IC, Cintra FA, Gallani MC. Psychometric properties of the Minnesota Living with Heart Failure--Brazilian version--in the elderly. Qual Life Res. 2007; 16(6): 997-1005. doi: 10.1007/ s11136-007-9170-z.

19. Ho CC, Clochesy JM, Madigan E, Liu CC. Psychometric evaluation of the Chinese version of the Minnesota Living with Heart Failure Questionnaire. Nurs Res. 2007; 56(6): 441-448. doi: 10.1097/01.NNR.0000299849.21935.c4.

20. Cronbach L. Coefficient alpha and the internal structure of test. Psychometrika. 1951; 16(3): 297-334.

21. Káiser H. An index of factorial simplicity. Psychometrika. 1974; 39: 32-36.

22. Bartlett M. Test of significance in factor analysis. Psychology. 1950; 3: 77-85.

23. Garin O, Ferrer M, Pont A, Wiklund I, Van Ganse E,
Vilagut G, et al. Evidence on the global measurement model of the Minnesota Living with Heart Failure Questionnaire. Qual Life Res. 2013; 22(10): 26752684. doi: 10.1007/s11136-013-0383-z.

24. Bilbao A, Escobar A, Garcia-Perez L, Navarro G, Quiros R. The Minnesota living with heart failure questionnaire: comparison of different factor structures. Health Qual Life Outcomes. 2016; 14: 23. doi: 10.1186/s12955-016-0425-7.

25. Tesio L. Measuring behaviours and perceptions: Rasch analysis as a tool for rehabilitation research. J Rehabil Med. 2003; 35(3):105-115.

26. Mogle J, Buck H, Zambroski C, Alvaro R, Vellone E. Cross-Validation of the Minnesota Living With Heart Failure Questionnaire. J Nurs Scholarsh. 2017; 49(5): 513-520. doi: 10.1111/jnu.12318.

27. Heo S, Moser DK, Riegel B, Hall LA, Christman N. Testing the psychometric properties of the Minnesota Living with Heart Failure questionnaire. Nurs Res. 2005; 54(4): 265-272.

28. Moon JR, Jung YY, Jeon ES, Choi JO, Hwang JM, Lee SC. Reliability and validity of the Korean version of the Minnesota Living with Heart Failure Questionnaire. Heart Lung. 2012; 41(1): 57-66. doi: 10.1016/j.hrtlng.2011.09.011.

29. Breidthardt T, Irfan A, Klima T, Drexler B, Balmelli C, Arenja N, et al. Pathophysiology of lower extremity edema in acute heart failure revisited. Am J Med. 2012; 125(11): 1124 e1- e8. doi: 10.1016/j. amjmed.2011.12.015.

30. Kataoka H. Clinical characteristics of lowerextremity edema in stage A cardiovascular disease status defined by the ACC/AHA 2001 Chronic Heart Failure Guidelines. Clin Cardiol. 2013; 36(9): 555559. doi: 10.1002/clc.22159.

31. Sztajzel J. Chronic heart failure and its consequences on the partner relationship. Rev Med Suisse. 2015; 11(498): 2313-2315.

32. Kitzman DW, Hundley WG, Brubaker PH, Morgan TM, Moore JB, Stewart KP, et al. A randomized double-blind trial of enalapril in older patients with heart failure and preserved ejection fraction: effects on exercise tolerance and arterial distensibility. Circ Heart Fail. 2010; 3(4): 477-485. doi: 10.1161/ CIRCHEARTFAILURE.109.898916.

33. Rector TS, Carson PE, Anand IS, McMurray JJ, Zile MR, McKelvie RS, et al. Assessment of longterm effects of irbesartan on heart failure with preserved ejection fraction as measured by the minnesota living with heart failure questionnaire in the irbesartan in heart failure with preserved systolic function (I-PRESERVE) trial. Circ Heart Fail. 2012; 5(2): 217-225. doi: 10.1161/ 
CIRCHEARTFAILURE.111.964221.

34. Edelmann F, Wachter R, Schmidt AG, KraigherKrainer E, Colantonio C, Kamke W, et al. Effect of spironolactone on diastolic function and exercise capacity in patients with heart failure with preserved ejection fraction: the Aldo-DHF randomized controlled trial. JAMA. 2013;309(8): 781-791. doi: 10.1001/jama.2013.905.

\section{Supplementary Material}

Supplementary Table S1. Internal consistency of the Minnesota Living with Heart Failure Questionnaire ( $\mathrm{n}=200)$.

\begin{tabular}{|c|c|c|c|c|c|}
\hline Item & Sign & $\begin{array}{l}\text { Item-test } \\
\text { correlation }\end{array}$ & $\begin{array}{l}\text { Item-rest } \\
\text { correlation }\end{array}$ & $\begin{array}{c}\text { Average inter-item } \\
\text { covariance }\end{array}$ & Alpha \\
\hline 1. Swelling in your ankles, legs & + & 0.5822 & 0.5341 & 1.0813 & 0.9103 \\
\hline 2. Resting during day & + & 0.7345 & 0.6966 & 1.0416 & 0.9066 \\
\hline 3. Walking or climbing stairs difficult & + & 0.7535 & 0.7141 & 1.0266 & 0.9059 \\
\hline 4. Working around house difficult & + & 0.7907 & 0.7561 & 1.0169 & 0.9049 \\
\hline 5. Away from home difficult & + & 0.7732 & 0.7353 & 1.0182 & 0.9053 \\
\hline 6. Sleeping difficult & + & 0.5716 & 0.5136 & 1.0697 & 0.9107 \\
\hline 7. Relating to or doing things with friends or family difficult & + & 0.6543 & 0.6091 & 1.0611 & 0.9086 \\
\hline 8. Working to earn a living difficult & + & 0.7733 & 0.7325 & 1.0087 & 0.9052 \\
\hline 9. Recreational activities difficult & + & 0.6852 & 0.6292 & 1.0242 & 0.9080 \\
\hline 10. Sexual activities difficult & + & 0.4893 & 0.4180 & 1.0811 & 0.9132 \\
\hline 11. Eating less foods I like & + & 0.4451 & 0.3842 & 1.1037 & 0.9133 \\
\hline 12. Shortness of breath & + & 0.6911 & 0.6498 & 1.0542 & 0.9078 \\
\hline 13. Fatigue & + & 0.7934 & 0.7627 & 1.0300 & 0.9052 \\
\hline 14. Hospitalization & + & 0.4095 & 0.3432 & 1.1080 & 0.9143 \\
\hline 15. Medical costs & + & 0.3486 & 0.2780 & 1.1199 & 0.9157 \\
\hline 16. Side effects from medications & + & 0.4084 & 0.3454 & 1.1108 & 0.9141 \\
\hline 17. Feeling burden to family or friends & + & 0.5497 & 0.4948 & 1.0813 & 0.9110 \\
\hline 18. Feeling loss of self-control & + & 0.5369 & 0.4816 & 1.0848 & 0.9113 \\
\hline 19. Being worried & + & 0.6079 & 0.5555 & 1.0655 & 0.9097 \\
\hline 20. Difficulty concentrating or remembering & + & 0.4493 & 0.3875 & 1.1017 & 0.9133 \\
\hline 21. Being depressed & + & 0.6208 & 0.5722 & 1.0674 & 0.9094 \\
\hline Test scale & & & & 1.0646 & 0.9137 \\
\hline
\end{tabular}

Supplementary Table S2. Kaiser-Meyer-Olkin (KMO) measure of sampling adequacy.

\begin{tabular}{|c|c|}
\hline Item & KMO \\
\hline 1. Swelling in your ankles, legs & 0.9469 \\
\hline 2. Resting during day & 0.9449 \\
\hline 3. Walking or climbing stairs difficult & 0.8850 \\
\hline 4. Working around house difficult & 0.9479 \\
\hline 5. Away from home difficult & 0.8805 \\
\hline 6. Sleeping difficult & 0.9451 \\
\hline 7. Relating to or doing things with friends or family difficult & 0.9522 \\
\hline 8. Working to earn a living difficult & 0.9219 \\
\hline 9. Recreational activities difficult & 0.9147 \\
\hline 10. Sexual activities difficult & 0.9334 \\
\hline 11. Eating less foods I like & 0.8967 \\
\hline 12. Shortness of breath & 0.9440 \\
\hline 13. Fatigue & 0.9132 \\
\hline 14. Hospitalization & 0.7203 \\
\hline 15. Medical costs & 0.7414 \\
\hline 16. Side effects from medications & 0.8842 \\
\hline 17. Feeling burden to family or friends & 0.8598 \\
\hline 18. Feeling loss of self-control & 0.8335 \\
\hline 19. Being worried & 0.8543 \\
\hline 20. Difficulty concentrating or remembering & 0.8377 \\
\hline 21. Being depressed & 0.8817 \\
\hline Overall & 0.9004 \\
\hline
\end{tabular}

KMO=Kaiser-Meyer-Olkin. 
Psychometric properties of the Minnesota Living with Chronic Heart Failure Questionnaire in a Colombian population

Supplementary Table S3. Extraction of factors of the Minnesota Living with Heart Failure Questionnaire ( $\mathrm{n}=200)$.

\begin{tabular}{lcccc}
\hline \multicolumn{1}{c}{ Dimension } & Eigenvalue & Difference & Proportion & Cumulative \\
\hline Physical & 6.43121 & 3.11483 & 0.3062 & 0.3062 \\
Emotional & 3.31639 & 1.71791 & 0.1579 & 0.4642 \\
Social & 1.59847 &. & 0.0761 & 0.5403 \\
\hline
\end{tabular}

Method: principal-component factors; Rotation: orthogonal varimax (Kaiser off); Likelihood Ratio test: independent vs. saturated: chi2(210) = 2126.20 Prob $>$ chi $2=0.0000$.

Supplementary Table S4. Standarized residuals variance, eigenvalues in the 1st contrast and general coefficients of correlation between residuals $(\mathrm{n}=192)$.

\begin{tabular}{|c|c|c|c|}
\hline Dimension & $\begin{array}{c}\% \text { Variance by } \\
\text { measures }\end{array}$ & $\begin{array}{l}\text { Eigenvalues unexplained } \\
\text { variance in 1st contrast }\end{array}$ & $\begin{array}{c}\text { Coefficients between } \\
\text { residuals }\end{array}$ \\
\hline Physical & 57.4 & 2 & All $<0.50$ \\
\hline Emotional & 54.0 & 1.7 & $19-20(-0.51)$ \\
\hline Emotional without item 20 & 59.1 & 1.7 & All $<0.50$ \\
\hline Social & 44.8 & 1.7 & All $<0.50$ \\
\hline Total & 42.0 & 3.3 & $19-21(0.52)$ \\
\hline
\end{tabular}

Supplementary Table S5. Severity levels, standard errors, and goodness-of-fit indices of the MLHF-Q emotional dimension without item 20 using Rasch analysis ( $\mathrm{n}=192)$.

\begin{tabular}{clccccc}
\hline \multirow{2}{*}{ Items } & \multicolumn{1}{c}{ Description } & (logit) & SE & \multicolumn{2}{c}{ MNSQ } \\
\cline { 4 - 6 } & & & & Infit & Outfit \\
\hline 17 & Feeling burden to family or friends & 0.29 & 0.08 & 1.21 & 1.18 \\
19 & Being depressed & -0.02 & 0.08 & 1.02 & 0.96 \\
18 & Being worried & -0.45 & 0.08 & 0.92 & 0.88 \\
\hline
\end{tabular}

$\mathbf{S E}=$ Standard error; $\mathbf{M N S Q}=$ Mean square fit statistic; $\mathbf{I n f i t}=$ Inlier-sensitive fit; Outfit=Outlier-sensitive fit.

Supplementary Table S6. Discriminatory capacity of the Minnesota Living with Heart Failure Questionnaire $(\mathrm{n}=200)$.

\begin{tabular}{|c|c|c|c|c|}
\hline Variable & $\begin{array}{c}\text { Physical Median } \\
\text { (Q1-Q3) }\end{array}$ & $\begin{array}{c}\text { Emotional Median } \\
\text { (Q1-Q3) }\end{array}$ & $\begin{array}{c}\text { Social Median } \\
\text { (Q1-Q3) }\end{array}$ & $\begin{array}{c}\text { Total Median } \\
\text { (Q1-Q3) }\end{array}$ \\
\hline \multicolumn{5}{|l|}{ Sex } \\
\hline Women & $15(4-26)$ & $9(4-15)$ & $16(9-23)$ & $43(23-58)$ \\
\hline Men & $10(3-22)$ & $7(3-12)$ & $16(10-21)$ & $35(19-53)$ \\
\hline $\mathrm{p}$-value & 0.433 & $0.047^{*}$ & 0.730 & 0.273 \\
\hline \multicolumn{5}{|l|}{ Age } \\
\hline$>65$ & $18(6-24)$ & $9(4-14)$ & $17(12-22)$ & $45(27-58)$ \\
\hline$\leq 65$ & $8(3-20)$ & $6(3-12)$ & $15(8-22)$ & $29(16-52)$ \\
\hline p-value & $0.002 *$ & $0.031 *$ & 0.182 & $0.005^{*}$ \\
\hline \multicolumn{5}{|c|}{ Functional class NYHA } \\
\hline III-IV & $27(21-32)$ & $12(8-18)$ & $23(18-27)$ & $61(53-77)$ \\
\hline I-II & $7(3-17)$ & $6(3-10)$ & $13(8-20)$ & $28(15-46)$ \\
\hline $\mathrm{p}$-value & $0.000^{*}$ & $0.000^{*}$ & $0.000 *$ & $0.000 *$ \\
\hline \multicolumn{5}{|l|}{ LVEF (\%) } \\
\hline$\leq 45$ & $18(8-23)$ & $8(4-14)$ & $14(7-20)$ & $45(23-58)$ \\
\hline$>45$ & $10(3-22)$ & $7(3-12)$ & $17(10-22)$ & $35(20-54)$ \\
\hline p-value & 0.146 & 0.267 & 0.177 & 0.556 \\
\hline
\end{tabular}

*=p-value $<0.05$ Mann-Whitney U test. Q1-Q3=First and third quartile; LVEF=Left ventricular ejection fraction; NYHA=New York Heart Association. 


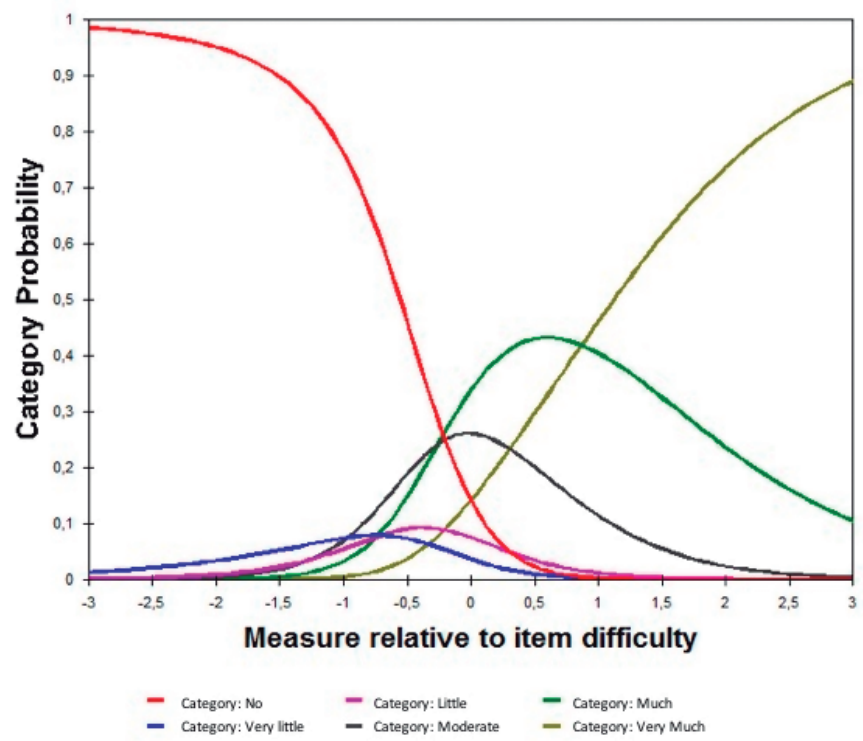

Supplementary Figure S1. Category probability curves.
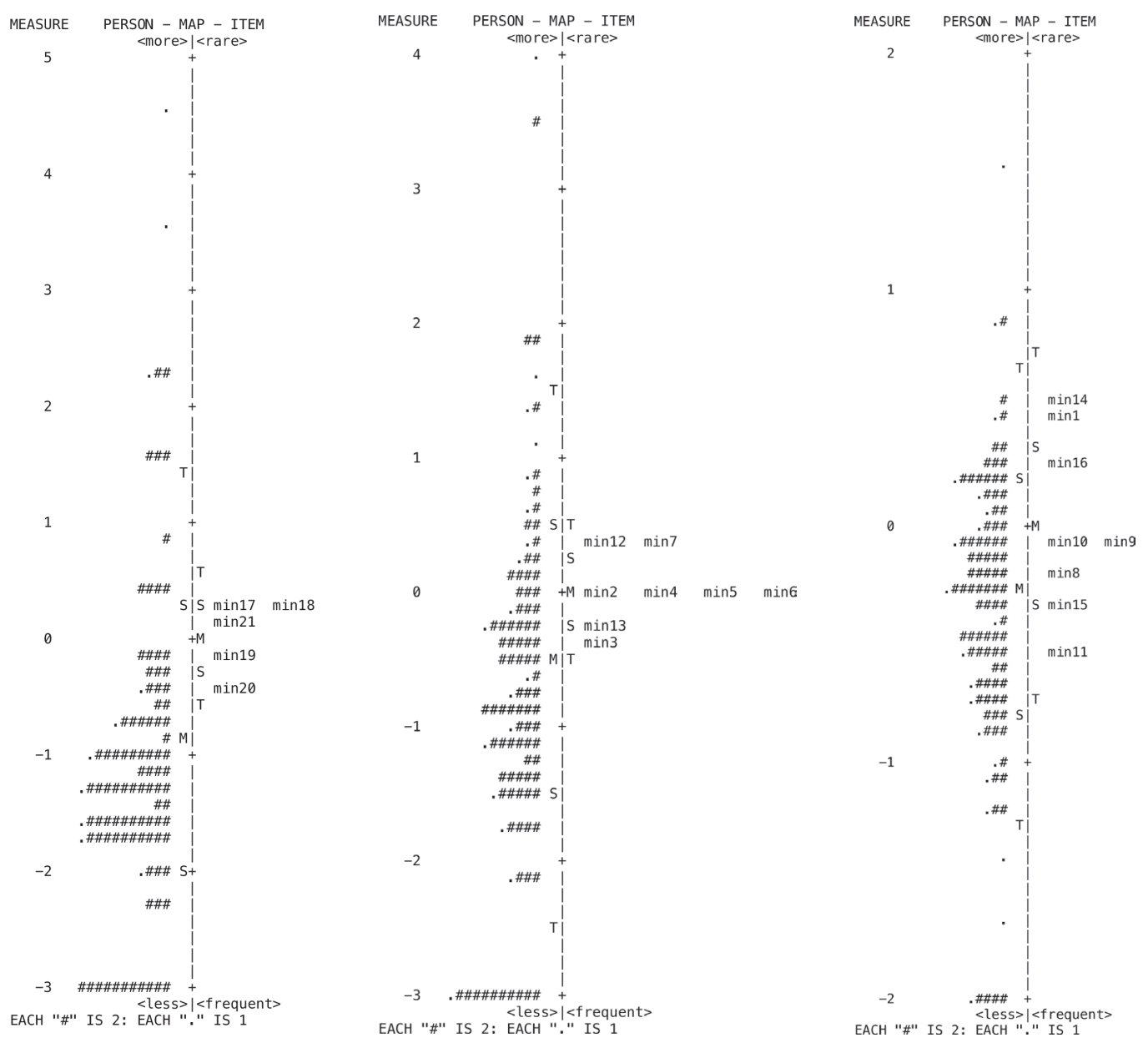

Supplementary Figure S2. Wright map for emotional, physical and social dimensions of the MLHF-Q using Rasch analysis (n=192). Each “\#” = 2 people; each "." = 1 person. 